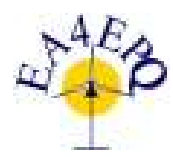

International Conference on Renewable Energies and Power Quality (ICREPQ'14)

Cordoba (Spain), $8^{\text {th }}$ to $10^{\text {th }}$ April, 2014

Renewable Energy and Pauer Quality. Fournal (RE\&PQJ)

ISSN 2172-038 X, No.12, April 2014

\title{
Impact of Plug-In Electric Vehicle Battery Charging on a Distribution System Based on Real-Time Digital Simulator
}

\author{
A. Alharbi, A. Eltom, and N. Sisworahardjo \\ Department of Electrical Engineering \\ The University of Tennessee at Chattanooga \\ Chattanooga, TN. 37403 (USA) \\ E-mail: Abdulelah009@gmail.com,Ahmed-Eltom@utc.edu,nurh@ieee.org
}

\begin{abstract}
Although the electric vehicles (EVs) have many economic and environmental advantages as compared to the conventional cars, the increased adoption of these vehicles will bring up new concerns for the power distribution grid in terms of introducing new peaks into the system or causing voltage quality problems. This study investigates the impact of the electric vehicles battery charging on the distribution system in terms of voltage unbalance at various locations, transformers overloading, and shifting the peak of the system. In this research, a $12.47 \mathrm{kV}$ real distribution network has been modelled using real time digital simulator, using real data from a power distributor. The study presents four different scenarios of uncoordinated EVs integration for two different charging times (evening and night) and two different charging rates (level I and level II) at different penetration levels ranging from $10 \%$ to $100 \%$. Voltage unbalance at different locations is determined and transformer overloading is analysed. The influence of EVs charging on the daily load curve is shown.
\end{abstract}

\section{Key words}

Distribution System, Electric vehicles, Real-Time Simulation, Transformer Overloading, Voltage Unbalance.

\section{Introduction}

Transportation and electricity generation are considered to be the contributing factors to air pollution and global warming. As a matter of fact, most of the power plants are built outside the cities; thus, conventional gasoline vehicles are considered to be the primary causes for contamination of air by smoke and harmful gases in urban areas. Conventional vehicles (CVs) add a considerable amount of air pollution every year. For instance, in the United States about 27 percent of global warming pollution are caused by gasoline vehicles, including cars, trucks, and buses [1]. Not only do conventional internal combustion engines contribute to environmental pollution but they also consume too much amount of oil. Approximately 430 million gallons of oil are used every day to fuel the conventional automobiles [2]. The bad consequences of pollution have given birth to the electrification of the transportation. Thus, the electric vehicle technology is the important promising solution to tackle this issue [3]. This solution leads automobile manufactures to shift and invest in the electric drive vehicles production.

In late $1800 \mathrm{~s}$, the first commercial electric car was launched in New York City [4]. Afterwards, the conventional and new auto manufactures entered the market of electric transportation. They invested and devoted their potentials into the technologies that would lead to producing zero or near zero emission vehicles. Currently, plug-in hybrid electric vehicles (PHEVs) reduce $\mathrm{CO} 2$ emission by $25 \%$ compared to conventional vehicles [5].

Clean Edge Site [6] confirms that there will be about two millions of electric vehicles (EVs) all over the world by 2015 while the United States official domestic is planning to have one million EVs by 2015 . This has been supported by the governments at all levels. Major automotive manufactures have introduced EVs into the market. Chevy Volt vehicles have been driven 187million electric miles. Manufacturers making EVs, including Nissan, Tesla, GM, Honda, Toyota, BMW, Mercedes, etc. have introduced their PHEVs in the U.S. market. It has been predicted that $50 \%$ of new cars will be electric vehicles models by 2020 [7].

Since the market of EVs is growing rapidly, challenges due to the penetration of the EVs need to be investigated. Therefore, the penetration of plug-in electric vehicles (PEVs) into the power grid is a considered topic this time. Most of the consumers need their PEVs' batteries to be charged as soon as they get home after their working hours. However, if all batteries start charging at the same time, assuming that they are at fully discharged state, the peak demand for the electrical grid will increase, the distribution transformer would be overloaded, the power 
quality and the reliability of the whole system would be degraded, and the utilities' machines (e.g. three phase induction machines) as well as customers' equipment could be potentially damaged. To overcome these issues, utilities need to reinforce their generation, transmission, and distribution infrastructure. Another recommended solution is that the utilities would either apply financial incentives for off-peak charging or utilize EVs' smart charging that enables communication between utilities and vehicles to control charging pattern [8].

\section{Electric vehicles characteristics}

The term electric drive vehicle actually includes several different vehicle technologies. The main types of electric cars available today are hybrid electric vehicle, battery electric vehicle, plug-in hybrid electric vehicle, and extended-range electric vehicle. Although these vehicles are different in terms of their operational characteristics, they are considered similar when viewed as electrical loads on the distribution grid.

Electric vehicles use different charging levels for charging their batteries. Based on the standard outlets, considering safety requirements, there are three charging levels (SAE J1772). A level I AC charger is suitable for home. It uses standard wall outlet of $120 \mathrm{~V} / 15 \mathrm{~A}$ and the maximum power up to $1.8 \mathrm{~kW}$ and usually requires 6 to 8 hours to fully charge the EVs' battery pack. A Level II charger commonly utilizes 208/240VAC single phase and 30A outlet [9] and can provide charging power up to $7.2 \mathrm{~kW}$. Thus, the EVs' battery can be charged in 2 to 3 hours depending on the battery capacity and the state of charge [10]. Level III which uses three-phase circuit is still under development.

\section{Distribution system configuration}

\section{A. Description of the System under Study}

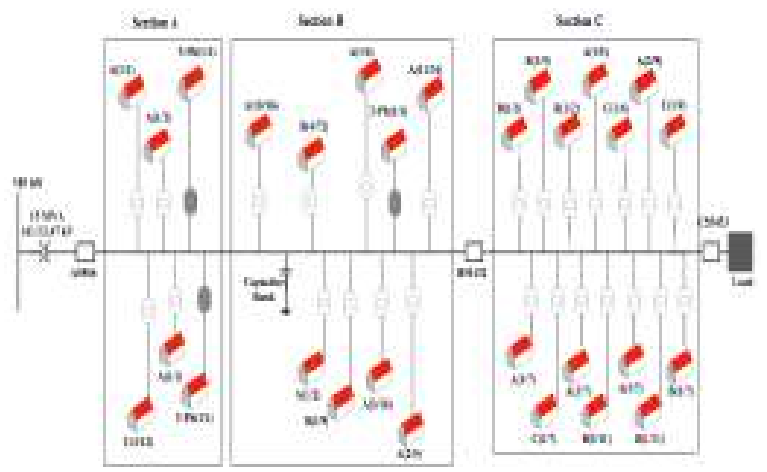

Fig. 1. Simplified Diagram of the Distribution System

Generally, a distribution system can be defined as all distribution infrastructures located beyond distribution substations [11]. In view of this, the system used in this study is a $12.47 \mathrm{kV}$ radial distribution system, representing a typical residential distribution network, receiving power from a substation that steps down the voltage from $161 \mathrm{kV}$ to $12.47 \mathrm{kV}$. The simplified diagram of this distribution system is shown in Fig. 1. The system is divided into three sections $\mathrm{A}, \mathrm{B}$, and $\mathrm{C}$. Each section consists of several laterals that have many distribution transformers of different sizes.

\section{B. System Data Analysis}

The studied distribution system consists of residential metered and primary metered customers. It has a total of 270 customers. Only three of them take their power from three-phase transformers directly. Further, 110 customers are on phase A, 123 residents are on phase B, and 34 customers are on phase $\mathrm{C}$. There are 61 service transformers, three of which are three phase while most of the single phase transformers are on phase A as 37 transformers connected to A-phase. In this system the service transformers' sizes typically range from 15 to 100 $\mathrm{kVA}$ for single phase and up to $500 \mathrm{kVA}$ in case of three phase.

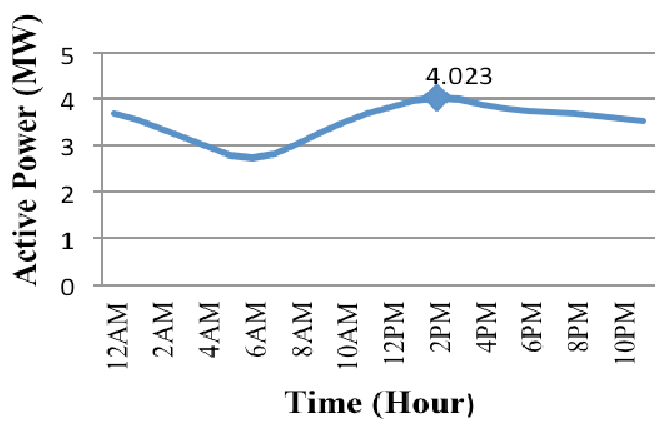

Fig. 2. Total Active Power of the System

While the main feeder is completely overhead line, the connected several branch lines are comprised of both overhead lines and underground cables. Most of the overhead lines, which made of Aluminum, have conductors' sizes ranging from 1033 Aluminum to 4/0 AL. The underground cable is represented by $1 / 0$ AlXLP conductor.

The load profile of the entire system, provided by the power distributor, covers 24 hours on a fifteen-minute time basis. The total active power that is supplied by the substation is shown in Fig. 2.

\section{Distribution system configuration}

\section{A. RT-LAB for Real Time Simulation}

Over the last two decades, thanks to the powerful and affordable computers, simulation software has got a rapid evolution from the slowly analog simulators to the highly sophisticated digital simulators. These digital simulators not only solve complex problems in less time but they also become widely available at a decreasing cost for every user.

The real-time simulation can be defined as a virtual model of an actual physical system that runs at the same rate as actual time [12]. The most important advantage of the real-time digital simulation is that it enables testing 
the simulated devices beyond their limits without the danger involved in testing real devices in the real world.

The RT-LAB ${ }^{\mathrm{TM}}$ software is modern design software that enables engineers and scientists to rapidly and easily converting Simulink ${ }^{\mathrm{TM}}$ dynamic models to real-time models with hardware-in-the-loop in less time. It is flexible enough to be applied to the most complex simulation and control problem, either for real-time hardware-in-the-loop applications or for speeding up model execution, control and test [13].

The real-time simulation is performed in a predetermined time interval (e.g., $1 \mathrm{~ms}, 5 \mathrm{~ms}$ or $20 \mathrm{~ms}$ ). During this time step, the processor must receive and read input data from other systems such as sensors and compute all necessary calculations like control algorithms. After completing the computations, the simulator writes all outputs. This predefined time step is normally known as fixed- step simulation.

To ensure a high speed real-time simulation with the improved accuracy of the results for the complicated power systems, the RT-LAB distributed processing software, in addition to the already existing SimPowerSystems blockset, comes with special Simulinkbased modeling toolboxes such as ARTEMiS and RTEvents [13].

RT-LAB utilizes Matlab/Simulink ${ }^{\text {TM }}$ to define models and corresponding parameters which will be executed by the real-time multi-processing system [14]. After implementing the system model using Matlab/Simulink ${ }^{\mathrm{TM}}$, a user must follow more several steps for the system to be realized in real-time with Opal-RT's software and hardware. First, regroup into different subsystems based on the state of every subsystem. Second, add the OpComm block(s) as necessary. Third, maximize parallel execution and state variable. Forth, set the real-time parameters.

\section{B. Model Construction}

The distribution system is modeled firstly using Matlab/Simulink ${ }^{\mathrm{TM}}$. Then, it has been modified to be realized in the RT-LAB environment. The three sections of the distribution network $\mathrm{A}, \mathrm{B}$, and $\mathrm{C}$ are divided into nine subsystems. Fig. 3 shows the Simulink model of the distribution system used in this study.

Due to the higher complexity of detailed model of each subsystem that leads to excessive overruns in real time simulation which increases the computation time considerably, RT-LAB software utilizes a number of decoupling tools from ARTEMiS block library to overcome this issue. These tools divide big matrices into multiple small state-space matrices which lead to quick and easier computation so the subsystems can then be processed in parallel using RT-LAB simulators [15]. In this study, since all distribution lines are less than 500 meters, the "StubLine" block from the ARTEMiS toolbox is used as a connection between subsystems.

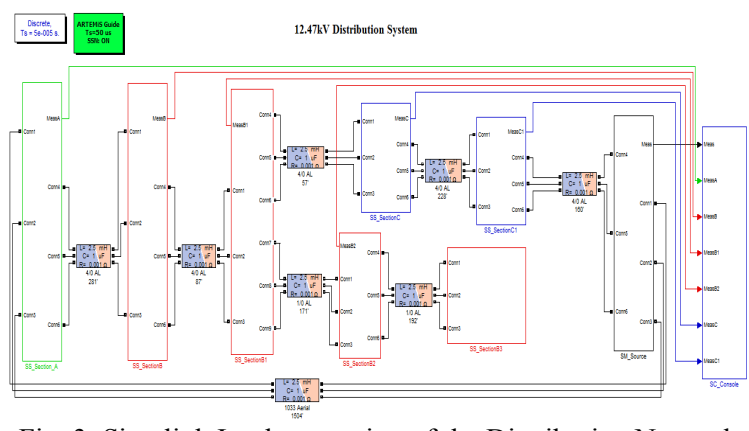

Fig. 3. Simulink Implementation of the Distribution Network

\section{Case Study and Results}

\section{A. Assumptions for Investigating PEVs' Charging Impact}

Most of the drivers arrive homes between 5 and 9 PM. Thus, evening at $6 \mathrm{PM}$ as well as night at $10 \mathrm{PM}$ are chosen to be the best times for the vehicles' owners to start charging their cars' batteries. Level I and level II are used to demonstrate the impact of PEVs' charging on the distribution system. Assuming energy conversion efficiency of $88 \%$, the maximum available output power form level I and level II chargers are $1.548 \mathrm{~kW}$ and 6.336 $\mathrm{kW}$, respectively. Depending on the penetration level, the charger's load is added to the existing load of the customer.

\section{B. Case Studies}

Four case studies are conducted to investigate the impact of PEVs' loads on the distribution residential network.

- Case I: charging PEV's' batteries using level I chargers in the evening.

- Case II: the vehicles' batteries are charged also in the evening using level II chargers.

- Case III: at night, level I chargers are used to charge the electric vehicles.

- Case IV: level II chargers are used to charge PEVs' batteries at night.

In the aforementioned scenarios, the penetration levels are considered from $10 \%$ to $100 \%$ PEVs' penetration in step of $10 \%$. In each penetration level, the PEVs' loads are added precisely to the selected customers based on load and the size of the service transformers.

\section{Impact on Voltage Unbalance}

Voltage unbalance can be defined as the ratio of the maximum voltage deviation from the average phase voltage to the average phase voltage. It has been noticed that the voltage unbalance increases as the penetration level increases. The percentage of voltage unbalance for level II charger reached $1 \%$ during $60 \%$ penetration level for evening charging and during 70\% of PEVs' charging at night. Figs. 4-7 demonstrate the $\%$ voltage unbalance for the four cases. 


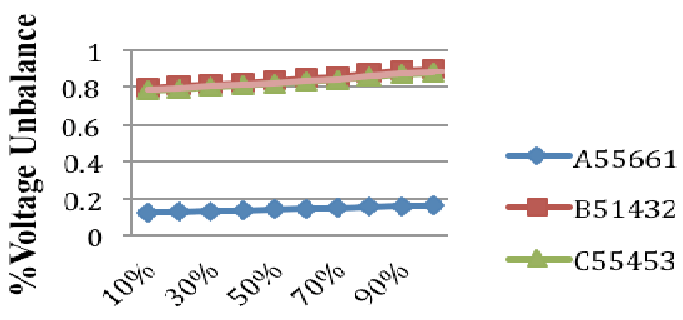

Penetration Level

Fig. 4. Voltage Unbalance for Level I Charger in the Evening

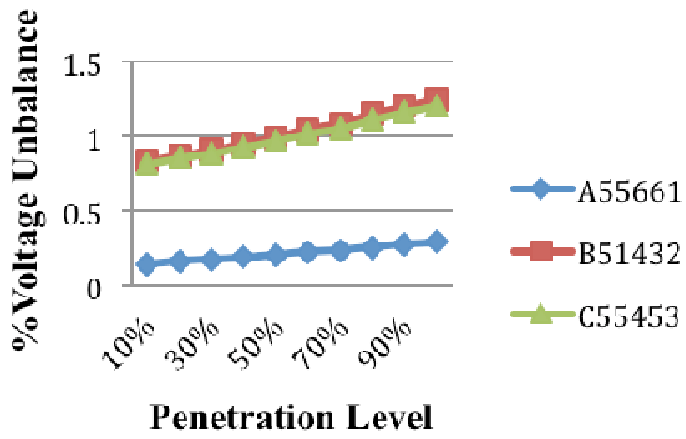

Fig. 5. Voltage Unbalance for Level II Charger in the Evening

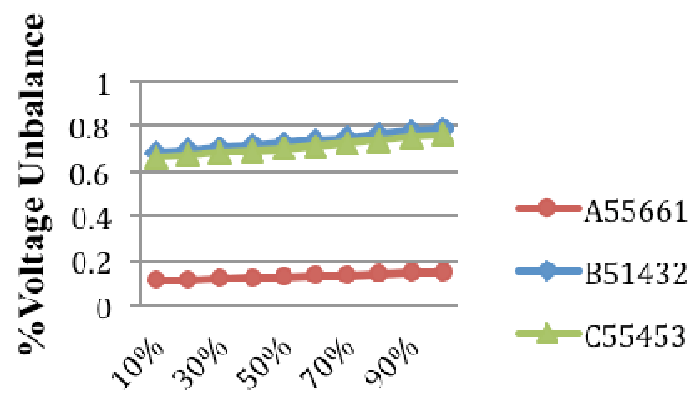

Penetration Level

Fig. 6. Voltage Unbalance for Level I Charger at Night

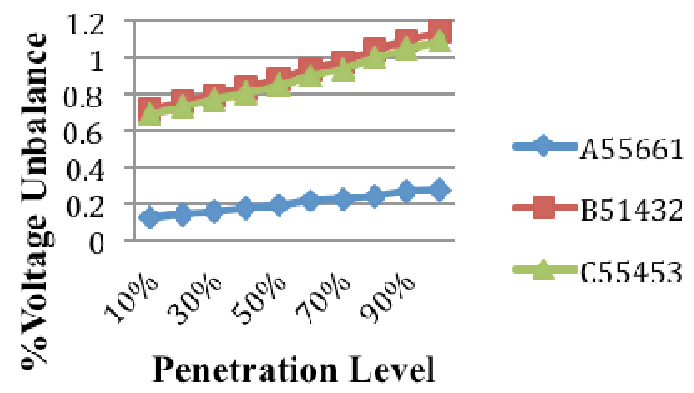

Fig. 7. Voltage Unbalance for Level II Charger at Night

\section{Impact on Peak Load}

Uncontrolled demands due to unmanaged PEVs charging either increase the peak demand or introduce a new peak load of the system. In both cases, additional investments on distribution infrastructure are necessary. Figs. 8-11 show the systems' load shape with PEVs' penetration for all scenarios. It has been observed that for $100 \%$ penetration level in the evening, the peak load increases to $5.445 \mathrm{MW}$ at $6 \mathrm{PM}$ compared to $4.023 \mathrm{MW}$ at the daily peak hour at 2:30 PM.

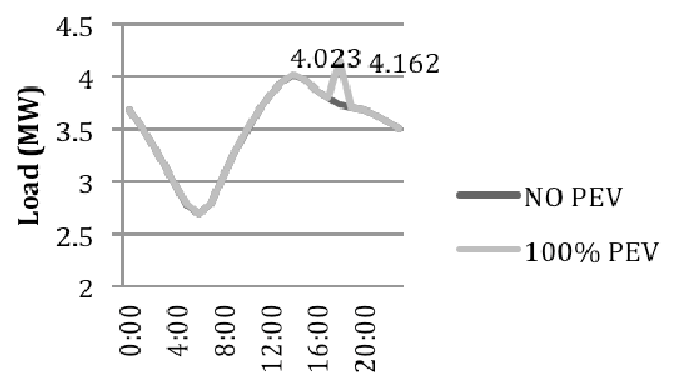

Time (Hour)

Fig. 8. Peak Load with Level I Charger in the Evening

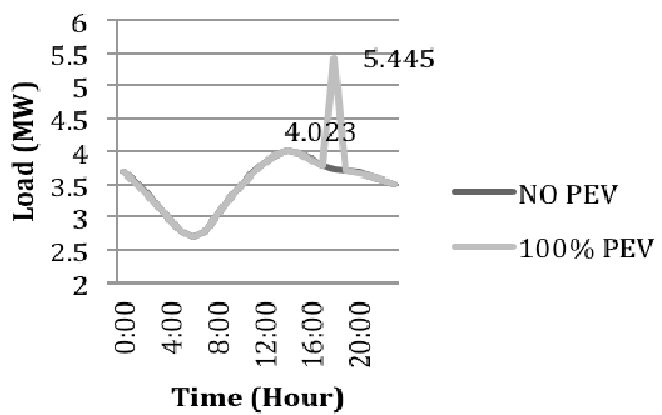

Fig. 9. Peak Load with Level II Charger in the Evening

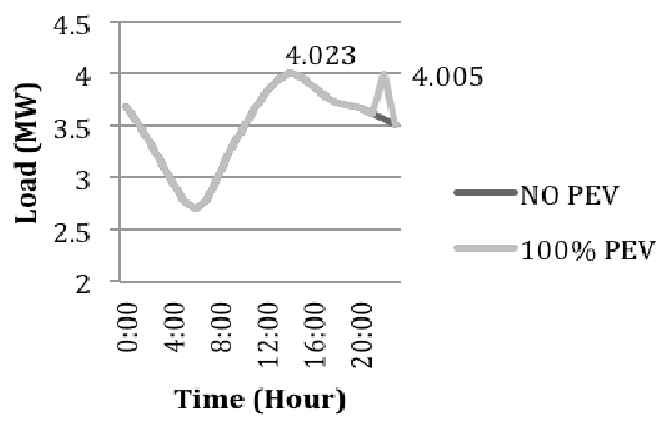

Fig. 10. Peak Load with Level I Charger at Night

\section{E. Impact on the Service Transformers}

Charging PEVs' using level II chargers causes a localized overload on the distribution transformers. It has been noticed that as the number of connected costumers increases the service transformers are highly susceptible to be overloaded. Most of the transformers are overloaded or close to be overloaded by the penetration level of $70 \%$ or more. Further, at $100 \%$ PEVs' penetration, most of the transformers carry as much as twice of their rated load. 


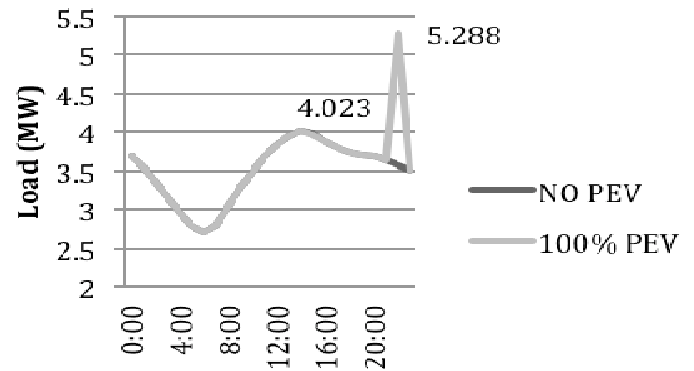

Time (Hour)

Fig. 11. Peak Load with Level II Charger at Night

\section{Conclusion}

Large-scale proliferation of plug-in electric vehicles in distribution systems will undoubtedly influence the design and the operation of the distribution network. The increased adoption of electric vehicles has a huge impact on some specifications of the distribution system such as voltage quality at load points and the load curve.

In this paper, a comprehensive analysis of the electric drives' charging impact on the distribution systems is investigated. A $12.47 \mathrm{kV}$ residential distribution system has been modeled in RT-LAB environment. This study focuses on the impact of PEVs' charging on different terms of the distribution system including, voltage unbalance, transformers overloading, and the daily load shape. It has been observed that the increased PEVs' penetration levels can dramatically affect the daily load profile, service transformers as well as the voltage quality.

Utilities should be able to handle the loads that are associated with EVs batteries' charging. Moreover, coordinated or "smart" charging is very essential to mitigate the disastrous consequences of EVs' penetration on the electrical grids. This controlled charging is an open research area which is currently under study.

\section{References}

[1] "The Next Generation Of Hybrid Cars: Plug-in Hybrids Can Help Reduce Global Warming and Slash Oil Dependency," N. R. D. Council, Ed., ed, July 2007, p. 4.

[2] M. Etezadi-Amoli, K. Choma, and J. Stefani, "Rapidcharge electric-vehicle stations," IEEE Transactions on Power Delivery, vol. 25, pp. 1883-1887, 2010.

[3] Z. Darabi and M. Ferdowsi, "Aggregated Impact of Plug-in Hybrid Electric Vehicles on Electricity Demand Profile," Sustainable Energy, IEEE Transactions on, vol. 2, pp. 501$508,2011$.

[4] International Energy Agency (IEA) and the Electric Vehicles Initiative of the Clean Energy Ministerial (EVI), "GLOBAL EV OUTLOOK: Understanding the Electric Vehicle Landscape to 2020," April 2013.

[5] C. H. Stephan and J. Sullivan, "Environmental and energy implications of plug-in hybrid-electric vehicles," Environmental Science and Technology, vol. 42, pp. 11851190, 2008.

[6] The Clean-tech Market Authority. (May 2013, July 2013). Plug-In Vehicle Sales Hit 100,000 in Past Two Years.
Available:

http://www.cleanedge.com/Resources/news/Plug-InVehicle-Sales-Hit-100\%2C000-in-Past-Two-Years

[7] K. Young, C. Wang, and K. Strunz, "Electric Vehicle Battery Technologies," in Electric Vehicle Integration into Modern Power Networks, ed: Springer, 2013, pp. 1556.

[8] A. Maitra, J. Taylor, D. Brooks, M. Alexander, and M. Duvall, "Integrating plug-in- electric vehicles with the distribution system," in 20th International Conference and Exhibition on Electricity Distribution, CIRED 2009, June 8, 2009 - June 11, 2009, Prague, Czech republic, 2009.

[9] S. S. Raghavan and A. Khaligh, "Impact of plug-in hybrid electric vehicle charging on a distribution network in a Smart Grid environment," in 2012 IEEE PES Innovative Smart Grid Technologies, ISGT 2012, January 16, 2012 - January 20, 2012, Washington, DC, United states, 2012

[10] S. Haghbin, S. Lundmark, M. Alakula, and O. Carlson, "Grid-connected integrated battery chargers in vehicle applications: Review and new solution," IEEE Transactions on Industrial Electronics, vol. 60, pp. 459473, 2013.

[11] S. Shao, M. Pipattanasomporn, and S. Rahman, "Grid integration of electric vehicles and demand response with customer choice," Smart Grid, IEEE Transactions on, vol. 3, pp. 543-550, 2012.

[12] Wikipedia, "Real-time simulation," ed, 2013.

[13] Opal-RT Technologies Inc, "RT-LAB User Guide," ed, 2007.

[14] K. Bao, "Battery Charge and Discharge Control for Energy Management in EDV and Utility Integration," Master of Science, Department of Electrical and Computer Engineering, The University of Alabama, Tuscaloosa, Alabama, 2012.

[15] Opal-RT Technologies Inc, "eMEGAsim and eDRIVEsim Product Information \& Simulation Application Examples," ed, 2009. 